\title{
Two cases of non-recurrent laryngeal nerve: routine nerve exploration in total thyroidectomy
}

Nazmi Yașar Sayım¹, Fethi Gül²

ABSTRACT

'Clinic of General Surgery, Kahta State Hospital, Adıyaman, Turkey ${ }^{2}$ Clinic of Anesthesiology, Kahta State Hospital, Adıyaman, Turkey

\section{Address for Correspondence Dr. Nazmi Yaşar Sayım Clinic of General Surgery, Kahta State Hospital, Adiyaman, Turkey Phone.: +90 4167255067 \\ e-mail: \\ nazmisayim@hotmail.com}

Received: 04.08.2011

Accepted: 31.10 .2011

(C) Copyright 2013 by Turkish Surgical Association

Available online at www.ulusalcerrahidergisiorg
Recurrent laryngeal nerve injury is one of the main complications of thyroidectomy. Since variability in the course of the nerve increases the risk of injury, routine nerve exploration is recommended. In this report, we present two cases of nonrecurrent laryngeal nerve found during total thyroidectomy performed for benign pathologies. Total thyroidectomy was performed on two female patients ( 52 and 54 years old) with a diagnosis of multi-nodular goiter in our clinics. Nerve exploration was performed routinely and non-recurrent laryngeal nerve was noted in both patients. Patients were discharged on the first postoperative day without any complications. Recurrent laryngeal nerve exploration does not increase the risk of nerve injury and ensures safety in case of non-recurrent laryngeal nerve presence, despite its rarity.

Key Words: Non-recurrent laryngeal nerve, total thyroidectomy, nerve exploration

\section{INTRODUCTION}

One of the most important complications in thyroidectomy is recurrent laryngeal nerve injury. The recurrent laryngeal nerve shows anatomical variations in its course. Rarely, the inferior laryngeal nerve can be non-recurrent. Due to differences in the anatomic course of the nerve, it is recommended that the nerve should be seen and protected to reduce the possibility of injury. Herein we report two cases that underwent total thyroidectomy for benign thyroid pathology and were detected to have non-recurrent inferior laryngeal nerve anomaly during nerve dissection.

\section{CASE PRESENTATION}

Two female patients aged 52 and 54 years andcomplaining of swelling in the neck were evaluated at the general surgery outpatient clinic. As a result of laboratory and imaging tests, surgery was recommended to both patients with a diagnosis of multi-nodular goiter. After routine preoperative preparation and anesthesiology evaluation, total thyroidectomy was performed. During surgery, standard recurrent laryngeal nerve dissection was performed in both the left and right sides. First by lateral approach, the nerve was dissected at the area where it courses close to the inferior thyroid artery. If the nerve could not be visualized at this level, dissection was carried on at the level of the ligament of Berry. In both patients, during dissection in the right lobe, the nerve was localized at the point of entrance to the larynx and tracing its course a type I non- recurrent laryngeal nerve abnormality was observed (Figure 1, 2). The patients were discharged on the first postoperative day, following withdrawal of the surgical drain, without any postoperative complications.

\section{DISCUSSION}

There are many variations of the recurrent laryngeal nerve. This increases the risk of nerve injury during thyroidectomy. The recurrent laryngeal nerve may be located in the trachea-oesophageal groove (50$77 \%)$, para-tracheal area (17-40\%), para-oesophageal area (6\%) or within thyroid parenchyma (4\%) (1). The recurrent laryngeal nerve can be divided into two or three branches before entering the larynx, in close proximity to the cricoid cartilage, and these branches also need to be protected during thyroidectomy (2).

The easiest point to reach the nerve during exploration of the inferior laryngeal nerve is the area where it courses close to the lower pole and in close proximity to the inferior thyroid artery. Although more difficult to dissect, the recurrent laryngeal nerve can also be observed at the level of the ligament of Berry since it is anatomically fixed $(3,4)$.

Very rarely recurrent laryngeal nerve is separated from the vagal nerve in the cervical region and is named non-recurrent laryngeal nerve. This anomaly is seen on the right with a rate of $0.6 \%$, and of 


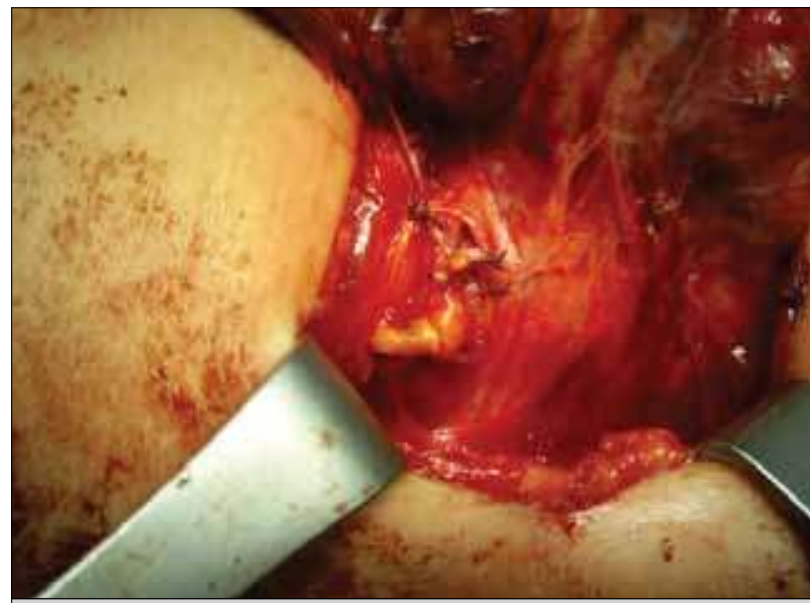

Figure 1. Right non-recurrent larngeal nerve from the first case

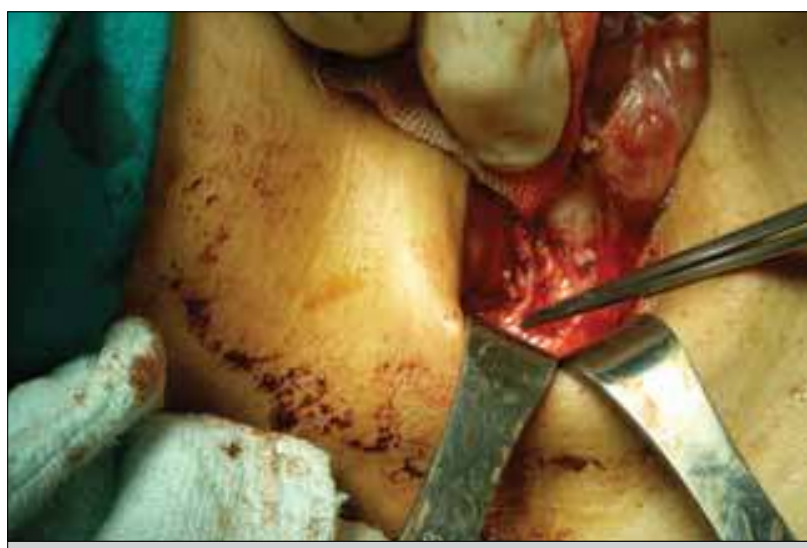

Figure 2. Right non-recurrent laryngeal nerve from the second case

$0.04 \%$ on the left. In both our cases, the non-recurrent laryngeal nerve was on the right side. There are types of non- recurrent laryngeal nerve. Type I: After leaving the vagus runs parallel to vessels at the level of the upper thyroid pole and enters the larynx with a short course. Type II: The nerve originates from the lower cervical region, turns up but is parallel to the inferior thyroid artery. Type lla: The nerve is parallel on the inferior thyroid artery. Type II b: The nerve is parallel below the inferior thyroid artery. In our cases, the non- recurrent laryngeal nerves coursed parallel to the superior thyroid vessels and directly entered the larynx and were evaluated as Type I. The right non-recurrent laryngeal nerve can be detected together with anomalies like the presence of aberrant subclavian artery and the absence of the innominate artery. Anomalies accompanying to left non-recurrent laryngeal nerve are right-sided aortic arch and situs inversus (5-8). The surgical importance of non-recurrent laryngeal nerve is due to its susceptibility to injury during thyroidectomy (9). Non- recurrent laryngeal nerve abnormalities are asymptomatic, can be recognized and protected during surgery if nerve exploration is done, otherwise the risk of injury is very high. Sanders et al. (10), in their 1000 thyroidectomies, found 7 non- recurrent nerves, and in two of these seven patients both a non- recurrent nerve and an additional recurrent branch were detected in the right side. They suggest a surgical dissection technique that demonstrates complete course of the nerves (10). In both our cases, we explored the nerve. When the nerve could not be visualized with standard dissection in the area in close relation to the inferior thyroid artery, dissection was performed at the level of the ligament of Berry. The nerves were detected at this level and were followed to the carotid sheath, revealing type I nonrecurrent laryngeal nerve anomaly in both cases.

\section{CONCLUSION}

One of the most important complications of thyroidectomy is recurrent laryngeal nerve injury. The recurrent laryngeal nerve shows anatomical variations in its course. Rarely, the inferior laryngeal nerve can be non-recurrent. Due to these anatomical differences, it is emphasized that a safe area to operate on cannot be defined without visualization of the nerve. In our clinic, we implemented total thyroidectomy as standard and we perform routine recurrent laryngeal nerve dissection during thyroidectomy. Recurrent laryngeal nerve dissection does not increase the risk of nerve damage and provides a safe surgery in also rare cases like non-recurrent laryngeal nerve abnormalities.

Peer-review: Externally peer-reviewed.

Author Contributions: Study concept and design - N.Y.S., F.G.; Acquisition of data - N.Y.S., F.G.; Analysis and interpretation of data - N.Y.S.; Preparation of the manuscript - N.Y.S.

Conflict of Interest: No conflict of interest was declared by the authors.

Financial Disclosure: The authors declared that this study has received no financial support.

\section{REFERENCES}

1. Zambudio AR, Rodríguez J, Riquelme J, Soria T, Canteras M, Parrilla P. Prospective study of postoperative complications after total thyroidectomy for multinodular goiters by surgeons with experience in endocrine surgery. Ann Surg 2004; 240: 18-25. [CrossRef]

2. Nemiroff PM, Katz AD. Extralaryngeal divisions of the recurrent laryngeal nerve. Surgical and clinical significance. Am J Surg 1982; 144: 466-9. [CrossRef]

3. Kasemsuwan L, Nubthuenetr S. Recurrent laryngeal nerve paralysis: a complication of thyroidectomy. J Otolaryngol 1997; 26: 365-7.

4. Friedrich T, Steinert M, Keitel R, Sattler B, Schönfelder M. [Incidence of damage to the recurrent laryngeal nerve in surgical therapy of various thyroid gland diseases--a retrospective study]. Zentralbl Chir 1998; 123: 25-9.

5. Sadler GP, Clark OH, Van Heerden JA, Farley Dr. Thyroid and Parathyroid. In: Principles of Surgery. 7th Ed: Schwartz SI, New York, MC Graw Hill. 1999: 1661- 713.

6. Skandalakis JE, Carlson GW, Colborn GL. Neck. In: Surgical Anatomy The embryological and Anatomic Basis of Modern Surgery. Int Ed: Skandalakis JE, Greece, Paschalidis Medical Publications 2004: 1-116.

7. Boger MS, Perrier ND. Advantages and disadvantages of surgical therapy and optimal extent of thyroidectomy for the treatment of hyperthyroidism. Surg Clin North Am 2004; 84: 849-74. [CrossRef]

8. Avisse C, Marcus C, Delattre JF, Marcus C, Cailliez-Tomasi JP, Palot JP, et al. Right nonrecurrent inferior laryngeal nerve and arteria lusoria: the diagnostic and therapeutic implications of an anatomic anomaly. Review of 17 cases. Surg Radiol Anat 1998; 20: 227-32. [CrossRef]

9. Kocatürk S, Yıldırım A, Kunt T. Non-recurrent nerve in thyroidectomy and its clinical importance: A case report. KBB-Forum 2004; 3: 89-91.

10. Sanders G, Uyeda RY, Karlan MS. Nonrecurrent inferior laryngeal nerves and their association with a recurrent branch. Am J Surg 1983; 146: 501-3. [CrossRef] 